\title{
PROPOSTA DE UMA SEQUÊNCIA DIDÁTICA PARA O ENSINO DO TEMA “ESTAÇÕES DO ANO" NO ENSINO FUNDAMENTAL
}

\author{
Camila Linhares Taxini* \\ Cintia Cristina Isicawa Puga** \\ Caio Samuel Franciscati Silva*** \\ Rosemary Rodrigues Oliveira****
}

RESUMO: Esta pesquisa objetivou desenvolver uma sequência didática para o ensino do tema "Estações do ano", capaz de proporcionar aos alunos uma visão global dos conteúdos envolvidos e as relações entre o saber científico e o cotidiano, na busca de se possibilitar que o conhecimento seja relacionado à estrutura cognitiva dos estudantes de modo significativo, sendo ancorado nela. Para o desenvolvimento das atividades de ensino foram utilizadas várias modalidades didáticas, tais como brainstorming, dramatização, jogo, pesquisa, problematização, vídeo, entre outras, na tentativa de se atender às diferenças individuais dos alunos. Os achados indicam que a sequência didática desenvolvida favoreceu os processos de ensino e aprendizagem. As produções dos alunos revelaram ainda que as atividades tiveram diferentes níveis de significância para os mesmos

Palavras-chave: aprendizagem significativa, ensino de ciências, ensino de astronomia.

\section{PROPOSAL OF A DIDACTIC SEQUENCE FOR THE TEACHING OF SEASONS OF THE YEAR IN BASIC EDUCATION}

ABSTRACT: This work aimed to develop a didactic sequence for teaching the theme "Seasons", apropiate to provide students with an overview of the content involved and the association between scientific knowledge and daily life, in an attempt to create a knowledge that is significantly anchored in the students cognitive structures. In order to reach the students' individualitites, many methods were used in the development of educational activities, such as brainstorming, drama, play, search, questioning, video, among others. The results indicated that the didactic sequence favored the development of teaching and learning processes. The students' productions also revealed that the activities have different levels of significance.

Keywords: significant learning, science education, astronomy education.

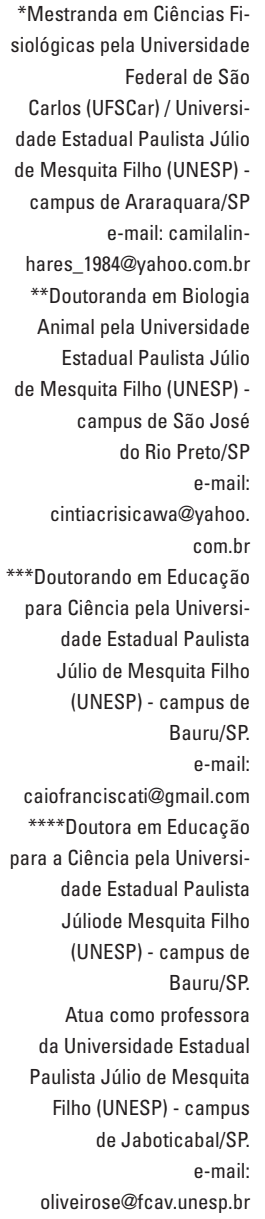


Camila Linhares Taxini|Cintia Cristina Isicawa Puga

Caio Samuel Franciscati Silva|Rosemary Rodrigues Oliveira

\section{INTRODUÇÃO}

A Astronomia nasceu junto com o homem. Desde a antiguidade o ser humano se interessava em desvendar os segredos do universo e relacioná-los com o seu cotidiano, fazendo da Astronomia uma das ciências mais antigas. Contudo, embora desde a antiguidade o homem possua muitos questionamentos acerca dos astros e tenha se utilizado dos conhecimentos advindos da Astronomia para calcular a época de cultivos ou de caça, e, ainda no século XXI, essa ciência seja capaz de associar o mais antigo ao mais moderno e abrir novos horizontes para a imaginação e a criatividade humanas, no ambiente escolar, a maneira como os conteúdos referentes à Astronomia são tratados faz muitas vezes com que os estudantes não consigam estabelecer relações entre os conteúdos desenvolvidos em sala de aula e seu cotidiano, e os alunos perdem sua curiosidade natural sobre o tema, o que impossibilita o desenvolvimento do espírito investigativo.

A Nova Proposta Curricular do Estado de São Paulo para o Ensino de Ciências (SÃO PAULO, 2008) bem como os Parâmetros Curriculares Nacionais de Ciências Naturais - PCN -, no eixo temático "Terra e Universo", sugerem que o estudo da Astronomia se dê no terceiro e no quarto ciclo do ensino fundamental (BRASIL, 2000). Nesses documentos oficiais são recomendadas observações sistemáticas do céu - movimentos aparentes das estrelas, da Lua, dos planetas e do Sol - como ponto de partida e atividade básica no estudo de Astronomia. O PCN relata ainda a importância da realização dessas observações antes mesmo do início das discussões dos modelos heliocêntrico e geocêntrico do sistema solar. Entretanto, apesar dessas recomendações para o favorecimento dos processos de ensino-aprendizagem referentes a essas temáticas, há dificuldades práticas, que residem no fato de as aulas muitas vezes ocorrerem no período diurno, impossibilitando a observação direta de muitos dos corpos celestes (estrelas, constelações e planetas).

Agravando essa dificuldade de ordem prática, a literatura sobre ensino de Ciências revela que há deficiências na formação dos professores, pois faltam a estes os conteúdos específico de Astronomia durante sua formação inicial e, de acordo com Lima (2006), quando o professor não tem o domínio do conteúdo científico, dificilmente conseguirá realizar adequadamente a transposição didática dos mesmos, tornando-se mero executor/seguidor de livros didáticos.

No que tange ao livro didático, a literatura pertinente aponta que poucas páginas desses materiais são destinadas aos conteúdos de Astronomia, sendo que muitos textos são pouco esclarecedores ou confusos, possuindo ainda erros conceituais e ilustrações em perspectivas obscuras, o que possibilita ou favorece que professores e alunos criem e/ou reforcem concepções distantes das aceitas cientificamente (CANALLE, 1999; LANGHI, 2004; LIMA, 2006; DIAS e PIASSI, 2007).

Do mesmo modo, na literatura pertinente, poucos são os trabalhos que apontam para estratégias de ensino de Astronomia que busquem cativar e aguçar 
a curiosidade de crianças, adolescentes e adultos (MEES, 2004). Nesse sentido, é importante, na elaboração e desenvolvimento de sequências de ensino, dentre outros aspectos, considerar as concepções prévias que os alunos possuem, na tentativa de se alcançar uma aprendizagem significativa. Segundo a perspectiva ausubeliana, uma das condições para a ocorrência da aprendizagem significativa é que o conceito a ser aprendido seja relacionável (ou apropriado) à estrutura cognitiva do aluno, de maneira não arbitrária e não literal, ou seja, deve existir uma relação lógica entre o novo conceito e a estrutura de conceitos que o aluno possui. Ainda nessa perspectiva, outra condição é que o aluno manifeste uma pré-disposição para relacionar de maneira substantiva e não arbitrária o novo conceito, potencialmente significativo, a sua estrutura cognitiva (MOREIRA, 1999).

Diante desse quadro, elaboramos uma estratégia de ensino de Astronomia, enfocando o tema "Estações do Ano". Para tanto, consideramos os conhecimentos prévios que os alunos possuíam sobre a temática abordada, utilizando-os como ponto de partida para o preparo das atividades desenvolvidas em sala de aula.

\section{METODOLOGIA}

Esta pesquisa foi desenvolvida junto a duas turmas de sétima série do ensino fundamental em uma escola estadual de ensino integral do município de Jaboticabal, em São Paulo, com 35 alunos em média por sala, com idade entre 13 e 14 anos. A sequência didática foi aplicada no segundo semestre do ano de 2008, em sete aulas de cinquenta minutos em cada turma, sendo estas desenvolvidas dentro da disciplina Ciências.

A elaboração e desenvolvimento da estratégia de ensino mencionada foi requisito para aprovação nas disciplinas Estágio Supervisionado e Práticas de Ensino do curso de Licenciatura em Ciências Biológicas da Faculdade de Ciências Agrárias e Veterinárias - UNESP, Campus de Jaboticabal.

O tema "Estações do Ano" foi escolhido a fim de se atender à Nova Proposta Curricular do Estado de São Paulo, uma vez que esse documento oficial sugere que os conteúdos referentes à Astronomia (movimento de translação da Terra ao redor do Sol; a invariância do eixo de rotação e o movimento de translação; translação da Terra e as estações do ano; estações do ano e variações climáticas; unidade de medida de tempo: um ano; calendários de diversas culturas; horário de verão: seu significado e impacto na conservação de energia e na saúde) sejam abordados durante o terceiro bimestre com os alunos da sétima série. Dentre os conteúdos elencados na proposta, trabalhamos com os conceitos de rotação e translação da Terra, medidas de tempo (dias, meses, anos), estações do ano, calendário e horário de verão.

A pesquisa das concepções prévias dos estudantes referentes à sucessão de dias e noites, estações do ano e duração do ano deu-se um mês antes do estabelecimento da sequência didática. por meio da aplicação de um questionário. 




Com o intuito de se colherem mais informações sobre as maneiras como os alunos compreendiam os temas citados, na primeira aula da sequência didática, por meio de um jogo do tipo "passa ou repassa", os alunos foram divididos em dois grandes grupos, em que cada grupo respondia a uma pergunta pré-estabelecida ou a passava para o outro grupo. As respostas dadas pelos estudantes, independentemente da coerência ou falta dela, foram anotadas e utilizadas como base para o desenvolvimento das próximas atividades da sequência de ensino.

No segundo encontro - em que se discutiu o tema "Movimentos de translação e rotação" -, questionamos os alunos sobre os movimentos de translação e rotação desenvolvidos pela Terra e, com o auxílio de um globo terrestre, demonstramos os movimentos e empreendemos discussões a respeito deles.

$\mathrm{Na}$ aula seguinte - sobre o tema "Proporção Terra-Sol" - construímos os conceitos de raio, diâmetro, relação e proporções espaciais. Para tanto, iniciamos com a problematização "Se o Sol possuísse $80 \mathrm{~cm}$ de diâmetro, qual seria o tamanho do nosso planeta?". Para a resolução desse problema, solicitamos que os alunos se dividissem em grupos e fornecemos a afirmação de que a "Terra é 110 vezes menor que o Sol". Após as discussões dos pequenos grupos e do grande grupo, realizamos uma aula expositiva-dialogada para a sistematização dos conteúdos abordados.

No quarto encontro - sobre "Simulação da Incidência de Luz Solar" -, utilizamos os seguintes materiais para a representação da Terra e seu eixo de inclinação: uma bola de isopor (Terra), uma vareta (eixo de inclinação da Terra em relação ao Sol) e uma lanterna (Sol). Para simular a incidência de luz solar em nosso planeta, propusemos as seguintes questões aos alunos: "Onde e como colocar a vareta?"; "Dias e noites, como são constituídos?"; "E o movimento de translação?"; "Há diferenças da incidência luminosa no Equador, nos trópicos e nos pólos?". Após esse momento, distribuímos um texto (desenvolvido por nós) para sistematizar o conteúdo discutido.

Ainda nessa aula, promovemos a dramatização do texto "Joãozinho da Maré" (CANIATO, 1983), no qual, após a identificação dos conflitos existentes pelos estudantes, foi proposto aos alunos um trabalho que consistia na elaboração de hipóteses capazes de auxiliar a se responder às dúvidas apresentadas por Joãozinho no texto.

No quinto encontro - sobre "Estações do Ano" -, iniciamos com uma dinâmica de tempestade cerebral sobre as estações do ano. Nessa dinâmica, perguntou-se aos estudantes: "O que vocês lembram quanto pensam em verão? E primavera? E outono? E inverno?". Ao longo da atividade anotamos na lousa as palavras ditas pelos alunos para posterior discussão com a classe. Os conhecimentos trabalhados nesse encontro foram as características naturais e culturais das estações do ano, já que as características das estações não são iguais em todos os lugares do planeta, e o porquê da existência de diferentes estações, ao mesmo tempo, em pontos distantes da Terra. Nessa aula também discutimos o horário de verão, buscando construir 
sua definição, existência e importância para a economia.

No encontro seguinte, realizamos uma avaliação na tentativa de identificarmos os conceitos de que os alunos se apropriaram e o modo como se deu essa apropriação. Para tanto, dividimos os alunos em dois grupos, e duas atividades foram realizadas paralela e alternadamente, pois estávamos em duas professoras nessa aula. A primeira atividade foi a busca por parte dos alunos de erros conceituais no vídeo "De onde vêm os dias e as noites?". Esse vídeo faz parte de uma coleção que se configura em uma série de desenhos animados brasileiros produzidos pela TV Escola. O desenho tem como objetivo tirar dúvidas corriqueiras de crianças de até 6 anos de idade e está disponível no site governamental Domínio Público. A segunda atividade - baseada no tema "Os calendários e a cultura" consistia em uma aula expositiva-dialogada sobre os calendários de diversas culturas e curiosidades sobre eles.

No último encontro dessa sequência, os alunos apresentaram seus trabalhos - as respostas a Joãozinho -, havendo uma discussão dessas respostas, na busca por se esclarecerem as dúvidas ainda existentes.

\section{A EXPERIÊNCIA PEDAGÓGICA - MOMENTOS SIGNIFICATIVOS}

O levantamento dos conhecimentos prévios dos alunos, tanto no questionário aplicado anteriormente ao estabelecimento da sequência didática quanto no jogo desenvolvido em seu primeiro encontro, relevou que os estudantes possuem concepções sincréticas sobre os fenômenos astronômicos, indo ao encontro do que é relatado pela literatura pertinente (DRIVER, 1989 citado por LANGHI, 2004; TIGNANELLI, 1998; LANGHI, 2004). Dentre essas ideias prévias, gostaríamos de destacar que os alunos compreendem a ocorrência das estações do ano como o maior e/ou menor afastamento da Terra em relação ao Sol, concepção esta encontrada também em professores do segundo ciclo do ensino fundamental em pesquisa desenvolvida por Leite (2002). Diante desses fatos, atentamos para a construção desses conceitos em sala de aula com o intuito de se favorecer uma maior aproximação das concepções dos estudantes aos conhecimentos científicos socialmente aceitos.

Dentro dessa perspectiva, no segundo encontro, construímos junto aos alunos os conceitos dos movimentos de rotação e translação descritos pela Terra e abordamos o fato de nosso planeta possuir uma inclinação de $23^{\circ}$ no eixo de rotação. Para tanto, questionamos os alunos sobre tais movimentos - "Vocês sabem o que é rotação? Vocês sabem o que é translação?"-, sendo que alguns estudantes responderam de modo adequado. Posteriormente, distribuímos o texto "Movimentos da Terra" (desenvolvido por nós) e, durante a leitura, explicávamos os conceitos abordados, sempre retomando as questões feitas na aula anterior.

As sistematizações das explicações deram-se no quadro-negro, e também utilizamos um modelo do globo terrestre como ferramenta auxiliar durante a cons- 
Camila Linhares Taxini|Cintia Cristina Isicawa Puga

Caio Samuel Franciscati Silva|Rosemary Rodrigues Oliveira

trução dos conteúdos abordados. Assim, foi possível apontar no globo as linhas imaginárias, os pontos cardeais, os hemisfério norte e sul e simular o movimento de rotação, fato que proporcionou a discussão sobre a sucessão de dias e noites. Dessa maneira, concordamos com Balbinott (2005), que diz que os modelos são alternativas para a visualização dos conteúdos, dado que neles são colocadas as características mais marcantes e significativas da realidade, respeitando-se a faixa etária do aluno.

Ainda nessa aula, abordamos o movimento aparente do Sol, a diferença da duração dos dias nas diferentes épocas do ano, os equinócios e os solstícios. Os alunos desconheciam a explicação para a ocorrência desses fenômenos. Acreditamos que tal fato ocorra porque esses assuntos geralmente são menos abordados em sala de aula, pois muitas vezes os professores não dominam esses saberes. Leite e Hosoume (2007) afirmam que os docentes pouco sabem sobre conceitos científicos envolvidos com o tema Astronomia, e assim eles se apegam aos conhecimentos fragmentados do livro didático, os quais também são insuficientes para explicar muitas das questões comumente presentes no estudo da Astronomia.

Durante as explicações sobre o movimento de translação, fora possível abordar com o auxílio do globo terrestre o fato de que a órbita terrestre é praticamente circular e evidenciar que há um ângulo de $23^{\circ}$ no eixo de rotação da Terra em relação à órbita. Nesse momento, com o intuído de romper com a falsa ideia de que apenas o afastamento da Terra em relação ao Sol seria responsável pelas estações do ano, introduzimos uma breve explicação de que o eixo de inclinação e o movimento de translação são os fatores que geram e definem as estações do ano. A explicação versou sobre as diferenças de incidência de luz solar no Equador e nos trópicos e o fato de que esse fenômeno também influencia as diferentes características das estações do ano nos diversos locais do planeta.

Iniciamos o terceiro encontro com a problematização "Qual o tamanho da Terra e do Sol?". Embora alguns alunos saibam que a Terra é muito menor em relação ao Sol, não conseguiram responder de imediato a tal questão. Em seguida, desenhamos no quadro-negro uma circunferência de $80 \mathrm{~cm}$ de diâmetro e pedimos que os alunos se dividissem em grupos para descobrirem o tamanho da Terra em relação ao tamanho do Sol desenhado para depois desenharem nosso planeta no quadro-negro. O problema gerou insatisfação e os alunos relataram que não era possível resolver tal questão pela ausência de dados que os subsidiassem na busca da resposta. Desse modo, oferecemos aos estudantes a informação de que o Sol é cento e dez vezes maior que a Terra.

Sendo assim, acreditamos que conseguimos construir uma verdadeira problematização, já que, de acordo com os PCNs, "uma questão toma a dimensão de um problema, quando suscita a dúvida, estimula a solução e cria a necessidade de ir em busca de informações para que as soluções se apresentem" (BRASIL, 1997, p.127). Ainda nessa perspectiva, Perrenoud (1999) afirma que os problemas têm que fazer sentido para que sejam significativos e que para solucioná-los os alunos devem criar estra- 
tégias. Dessa forma, a geração de uma problematização abriu um espaço favorável para a conversação sobre o assunto e ao mesmo tempo para a abordagem dos conceitos matemáticos de raio, diâmetro e regra de três, dado que os alunos apresentaram dificuldades em desenvolver o problema, já que os conceitos matemáticos envolvidos ainda eram muito abstratos para esses estudantes.

Após a resolução do problema pelos alunos, os grupos desenharam representações da Terra no quadro (Figura 1), mas apenas um grupo chegou à resposta correta sobre a proporção existente entre Sol e Terra. Tal fato vai ao encontro do descrito por Canalle e Moura 1995, que afirmam que, mesmo que em alguns livros apareça uma tabela com os diâmetros do Sol e dos planetas, a interpretação dos alunos em relação a ela não é efetiva, pois muitos não conseguem imaginar essas diferenças de tamanho apenas visualizando os números dos diâmetros.

Figura 1. Atividade sobre a proporção Sol-Terra. Fonte: Camila Linhares Taxini e Cintia Cristina Isicawa Puga.

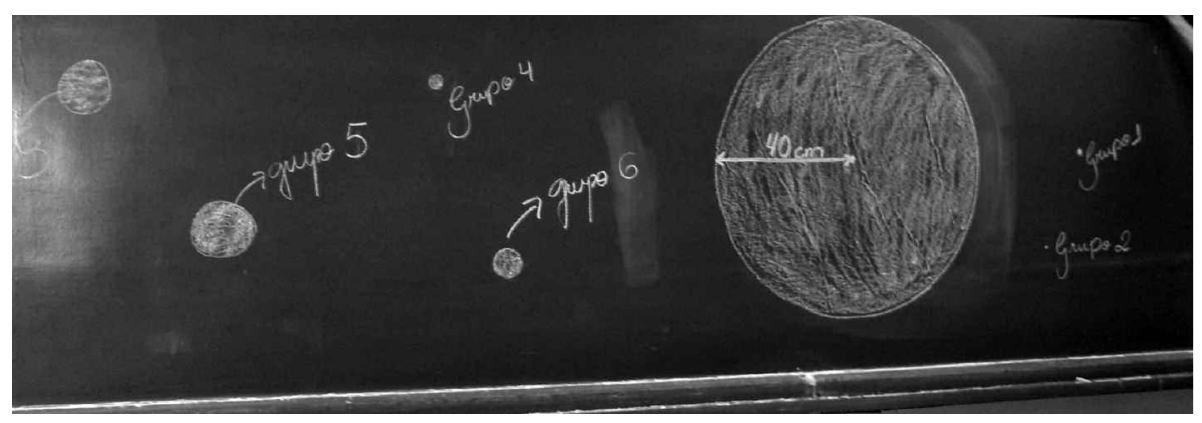

Ao final desse encontro, discutimos a importância da proporção, já que figuras contidas nos livros e na internet geralmente apresentam uma proporção incorreta entre os corpos celestes. Esse erro conceitual presente nessas ilustrações é explicado pela dificuldade em se desenharem os detalhes dos planetas em escala. Tal fato merece destaque, dado que diversas pesquisas mostram que em alguns livros o Sol tem dimensões menores do que a Terra, que a representação real do Sistema Solar em escala faria com que a figura perdesse seu valor teórico e que há ausência de escalas e legendas nessas ilustrações astronômicas (TREVISAN et al, 1997; CANALLE e OLIVEIRA, 1994).

A fim de verificar o quão significativa foram as aulas até o momento, empreendemos no quarto encontro questionamentos sobre os assuntos trabalhados, mas estes se deram de uma maneira diferente das utilizadas até então, com o intuito de se favorecerem situações para que os alunos aplicassem e relacionassem os saberes construídos. Para tanto, levamos um globo de isopor simulando a Terra e uma vareta simulando o eixo de rotação do planeta e, juntamente com os alunos, discutimos como a vareta deveria ser inserida no globo. Os estudantes relacio- 
Camila Linhares Taxini|Cintia Cristina Isicawa Puga

Caio Samuel Franciscati Silva|Rosemary Rodrigues Oliveira

naram este questionamento com a aula anterior respondendo que o eixo de inclinação da Terra deveria possuir um ângulo de $23^{\circ}$. Na sequência realizamos uma simulação dos movimentos de rotação e translação da Terra com o globo de isopor. Nesse momento, os alunos descreviam como deveriam ser efetuados os movimentos. Durante essa atividade um aluno questionou o tamanho da lanterna utilizada na atividade para representar o Sol, afirmando que ela era muito pequena, evidenciando ter relacionado o conceito de proporções abordado anteriormente com a simulação desenvolvida, mostrando-nos que a problematização da aula anterior fora significativa, já que os estudantes conseguiram transportar o conhecimento adquirido a outro contexto, durante essa aula.

Nessa perspectiva, os alunos relacionaram e aplicaram os conceitos anteriormente trabalhados em outra situação de ensino-aprendizagem. Segundo a perspectiva ausubeliana, para saber se a aprendizagem de um aluno foi significativa, devemos formular questões e problemas de uma maneira diferente, a qual demanda uma máxima transformação do conhecimento adquirido e de sua aplicação de forma não arbitrária e não literal (MOREIRA, 1999).

A Astronomia, por ser um tema abstrato, possibilita o surgimento de muitas dúvidas e, nessa aula, um aluno questionou sobre o movimento de "interlação" entre os planetas. Ao pesquisarmos o termo, percebemos o quanto a mídia exerce influências na vida e nos conceitos dos alunos e, consequentemente, interfere na sala de aula. A palavra "interlação" faz parte de um verso da música: "Uma Arlinda Mulher" (Mamonas Assassinas 1 ) - "Te ensinei todos os altos reversos e da vida e o movimento de interlação que faiz a terra gira!". Diante desse fato percebemos que a menção dos "movimentos da Terra" em sala de aula levou esse aluno a buscar, em sua rede cognitiva, suas concepções e vivências sobre o tema, de modo que o ele conseguiu associar os significados compartilhados em sala de aula à palavra "interlação", constante nos versos da música. Isso vai ao encontro do descrito pela teoria ausebeliana, a qual afirma que para conferirem significados aos novos conceitos, os estudantes os associam aos saberes já existentes em sua estrutura cognitiva (PUZZO et al., 2004).

Foi discutido com o aluno o verso da canção mencionada de modo que ele associasse o movimento descrito em "faiz a Terra girá" aos movimentos reais executados pelo planeta Terra e, consequentemente, investigasse os possíveis significados da palavra "interlação" dentro do contexto da canção.

Outra questão levantada nessa aula por um aluno foi o fenômeno do alinhamento dos planetas. O estudante gostaria de saber se esse fenômeno é reale com qual frequência ele ocorre (o tema levantado pelo aluno é comumente explorado em filmes de ficção científica e mesmo em produções voltadas para o público infantil, como o "Castelo Ra-tim-bum - o filme" no qual o alinhamento dos planetas é um evento que fortalece os poderes de todos os magos). Ao pesquisarmos o assunto, encontramos apenas informações vagas ou pouco confiáveis. A informação contida nos livros e na internet são falhas, ou muitas vezes contêm con- 
ceitos contraditórios, dificultado assim a exploração de assuntos astronômicos por parte dos professores. Esse fato talvez seja o motivo principal que os levem a sentirem-se inseguros frente a esses conteúdos, tornando o trabalho mais árduo devido à ausência de literatura adequada sobre esses temas, o que deixa os professores hesitantes e os leva a apegarem-se aos livros didáticos de modo acrítico (LEITE e HOSOUME, 2007).

Ao final dessa aula, realizamos uma dramatização do texto "Joãozinho da Maré" (CANIATO, 1983), o qual discute a história de um menino que confronta o que vê nas ruas e o que sua professora ensina, questionando-a. No texto, como a professora não está habituada ao aluno questionador, esta o ignora, e as questões de Joãozinho ficam sem resposta. Assim, após a dramatização do texto propusemos que os alunos entregassem ao final dos encontros uma redação que respondesse às dúvidas de Joãozinho. Para tanto, os alunos poderiam efetuar pesquisas em livros, jornais e internet na tentativa de responderem às questões expressas no texto de forma coerente e concisa.

A compreensão das influências das estações do ano na vida e na sociedade fora favorecida no quinto encontro. Neste, realizamos o levantamento dos conhecimentos dos alunos sobre as características das estações do ano. Para tanto, utilizamos a dinâmica da tempestade cerebral (brainstorming), pois, segundo Antunes (2004), essa técnica tem por princípio que os participantes apresentem as mais diversas ideias, mesmo que descabidas, sobre um assunto qualquer levantado. Anotamos as ideias expostas pelos alunos, instigando-os e incentivando-os a rápida sucessão de opiniões sem fazer qualquer juízo crítico da validade delas.

Nessa atividade dividimos o quadro-negro em quatro partes e nomeamos cada uma com as estações do ano. Em seguida, realizamos as seguintes questões: "O que vocês lembram quanto pensam em verão? E primavera? E outono? E inverno?" e anotamos cada resposta em seu respectivo espaço no quadro-negro (Tabela 1).

Ao analisarmos as ideias expostas pelos alunos, notamos que a maioria dos estudantes tem a visão de que as estações do ano têm características fixas (neve, gelo, flor). Tais concepções são frutos da herança da colonização europeia, já que na Europa e na Ásia as condições climáticas das quatro estações são bem distintas: o inverno se associa ao frio; a primavera a flores; o verão, ao calor; o outono, à queda de folhas (LIMA, 2006). Nessa perspectiva, a associação realizada pelos alunos pode estar associada à maneira superficial e geradora de incompreensões e erros através da qual os livros didáticos de Ciências e Geografia abordam a temática "Estações do Ano" (BIZZO, 1996; TREVISAN et al., 1997; CANALLE et al., 1997; DIAS e PIASSI, 2007;). Dessa forma, destacamos a importância de se tratar esse tema em sala de aula de forma a se desmistificarem e a se superarem os conceitos errados comumente veiculados pelos manuais didáticos. 
Camila Linhares Taxini|Cintia Cristina Isicawa Puga

Caio Samuel Franciscati Silva|Rosemary Rodrigues Oliveira

Tabela 1 - Palavras do "Brainstorm sobre Estações do Ano"

\begin{tabular}{|c|c|c|}
\hline ESTAÇÕES DO ANO & $7^{a} \mathrm{~A}$ & $7^{\mathrm{a}} \mathrm{B}$ \\
\hline VERÃO & $\begin{array}{l}\text { Calor, chuva, sol, bronzeado, } \\
\text { piscina, pipa, ventilador, praia, } \\
\text { sorvete, férias, biquíni, dormir. }\end{array}$ & $\begin{array}{l}\text { Calor, sol, chuva, praia, piscina, } \\
\text { sorvete, carnaval, beijo. }\end{array}$ \\
\hline PRIMAVERA & $\begin{array}{l}\text { Flores, frutas, pássaros, } \\
\text { verduras, legumes. }\end{array}$ & Flor, ramos. \\
\hline OUTONO & $\begin{array}{l}\text { Folha, árvores sem folhas, } \\
\text { vento, poeira. }\end{array}$ & $\begin{array}{l}\text { Folha caindo, folha seca, vento, } \\
\text { equinócio. }\end{array}$ \\
\hline INVERNO & $\begin{array}{l}\text { Frio, neve, gelo, pinheiro, } \\
\text { agasalho, natal (Papai Noel), } \\
\text { cobertor, chocolate quente, } \\
\text { dormir, namorar. }\end{array}$ & $\begin{array}{l}\text { Frio, neve, chuva, agasalho, } \\
\text { edredon, chocolate quente } \\
\text { cobertor. }\end{array}$ \\
\hline
\end{tabular}

Ainda nesse contexto, um dos alunos mencionou que "Não é verdade que tem flores só na primavera! É inverno e os ipês estão com flores!"; outro aluno disse "Nem todas as árvores ficam sem folhas no outono, depende da árvore. A minha nunca ficava sem todas as folhas". Com essas afirmações notamos que alguns alunos relacionaram a vivência cotidiana com os temas trabalhados na escola, fato este que deve ser estimulado por nós, professores, para que os alunos possam relacionar e aplicar os conhecimentos socialmente construídos em suas vidas, isto é, para que a aprendizagem de nossos estudantes seja significativa. Ainda durante a discussão, enfatizamos novamente que não é a variação das distâncias entre a Terra e o Sol que causa as diferentes estações do ano, pois, segundo Lima et al. (2004), citado por Lima (2006),

(...) uma das ideias mais corriqueiras está no fato do professor associar que, quando se está perto de uma fonte térmica, esta provoca um aumento da temperatura ao seu redor e, quando se afasta, a temperatura tende a diminuir. Ao estudar as estações do ano os alunos associam que é verão quando a Terra está próxima do Sol; por outro lado, o inverno ocorre quando a Terra está distante do Sol (LIMA et al., 2004 citado por LIMA, 2006 p. 48)

Ainda nessa atividade, foram discutidas características naturais e culturais relacionadas às estações do ano, ressaltando-se junto aos alunos que essas características não são iguais em todos os lugares da Terra, pois, segundo Sobreira (2002), "o estudo das estações do ano é de suma importância para o entendimento das diferentes paisagens climáticas, botânicas, dos ciclos agropecuários [...]”.

Também merece destaque o fato de que, quando questionados sobre aquilo de que se lembravam quando pensavam no inverno, alguns alunos responderam "Papai Noel" e "árvore de Natal". Nesses momentos, outros estudantes relacio- 
naram a resposta dada à história de Joãozinho e questionaram os colegas o porquê desse pensamento, dado que no Brasil é verão nessa época, fato que possibilitou novamente a discussão sobre a existência de diferentes estações do ano ao mesmo tempo no planeta. Nessa aula, observamos que os alunos novamente aplicavam e relacionavam os conhecimentos construídos nas aulas anteriores, evidenciando que os significados e sentidos compartilhados entre professores e alunos estavam adquirindo significância.

Os conceitos referentes às diversas formas de se medir o tempo, que dependem da referência histórico-social de cada povo, foram desenvolvidos no sexto encontro. Neste, os estudantes foram divididos em dois grupos, sendo que, enquanto um grupo participava da construção de conceitos referentes aos calendários, o outro desenvolvia atividades sobre o vídeo "De onde vem o dia e a noite?", produzidos pela TV Escola. Optamos por desenvolver as atividades dessa maneira porque a falta de um aparelho de TV grande o suficiente para que todos os alunos pudessem acompanhar a exposição do filme não permitiu que trabalhássemos com todos os estudantes ao mesmo tempo. Dessa maneira, as atividades ocorreram alterna e paralelamente.

Para o desenvolvimento da atividade com o vídeo, inicialmente assistimos a ele uma vez com os alunos, para que estes se familiarizassem, e, em seguida, explicamos que devemos utilizar nossos conhecimentos para questionar o mundo e as informações que nos são oferecidas. Sendo assim, assistimos novamente ao filme e solicitamos que os alunos assumissem uma postura de pesquisadores "Usando todo o nosso conhecimento, vamos achar alguns erros que o filme contém". Nessa atividade, intencionamos levar ao aluno a visão de Ciência como algo mutável e acessível, além de ser um processo e produto da ação humana.

A utilização do vídeo como modalidade didática deu-se da maneira descrita por Arroio et al. (2005), que dizem que, para um filme ter uma função investigativa, faz-se necessário trabalhá-lo com uma atividade paralela, como um roteiro, por exemplo, para que, ao dar sequência à aula, alunos e professores possam discutir as informações extraídas do vídeo. Em relação ao filme utilizado, Fonseca (2006) afirma que a série de filmes da coleção "De onde vem?", produzidos pela TV Escola, leva ao aluno a iniciação científica, devido ao fato que o estudante observa uma menina que questiona o mundo que a cerca. $\mathrm{O}$ autor também menciona que as respostas científicas não são intocáveis, e a Ciência, no filme, não é tratada como inatingível, já que são elementos comuns do dia-a-dia do aluno que respondem às questões, como o Sol, por exemplo, que respondia às questões de Kika sobre a sucessão de dias e noites.

A descoberta, por parte dos alunos, de dois erros no filme nos indicaria que eles estavam se apropriando dos conteúdos construídos até o momento. Os erros identificados eram as ausências de inclinação no eixo de rotação da Terra e de proporção entre Sol e Terra. Todavia, os alunos observaram vários detalhes do vídeo, encontrando muito mais erros do que o esperado (Tabela 2). 
Camila Linhares Taxini|Cintia Cristina Isicawa Puga

Caio Samuel Franciscati Silva|Rosemary Rodrigues Oliveira

Tabela 2 - Erros encontrados pelos alunos no vídeo “De onde vem o dia e a noite?"

\begin{tabular}{|l|l|l|}
\hline \multicolumn{3}{|c|}{ Erros encontrados pelos alunos durante a atividade } \\
\hline \multirow{4}{*}{$\begin{array}{l}\text { Movimentos de rotação } \\
\text { e translação }\end{array}$} & $\begin{array}{l}\text { "Rotação muito rápida... Não } \\
\text { dura um dia?" } \\
\text { "A Terra não está inclinada aí." } \\
\text { "A Terra não roda tão rápido." } \\
\text { "Só tem rotação, translação } \\
\text { não!" }\end{array}$ & $\begin{array}{c}\text { "Enquanto a Terra está em ro- } \\
\text { tação, não está em translação." } \\
\text { "A translação está redonda, e a } \\
\text { Terra não está em rotação." } \\
\text { "Está rodando muito rápido... } \\
\text { Não dura um ano?" }\end{array}$ \\
\hline Proporção Sol- Terra & $\begin{array}{l}\text { "A Terra é bem menor que } \\
\text { o Sol." } \\
\text { "O tamanho da Terra não é bem } \\
\text { menor que o Sol?" }\end{array}$ & $\begin{array}{l}\text { "O tamanho da Terra tá quase } \\
\text { do tamanho do Sol" }\end{array}$ \\
\hline Distância Sol- Terra & $\begin{array}{l}\text { "Sol muito perto da Terra." } \\
\text { "Sol tá relando na Terra." } \\
\text { "A Terra tá pertinho do Sol." }\end{array}$ & $\begin{array}{l}\text { "A distância da Terra e do Sol é } \\
\text { curta (...). Se fosse desse jeito } \\
\text { iríamos fritar e virar palito." }\end{array}$ \\
\hline \multirow{3}{*}{ Outros } & $\begin{array}{l}\text { "A Lua é redonda. A gente é } \\
\text { que vê ela dessa forma por } \\
\text { causa da iluminação do Sol." } \\
\text { "O Sol não fala." } \\
\text { "Nesta aí tem dois sóis." } \\
\text { "A Terra está redondinha." } \\
\text { "Não tem outros planetas." }\end{array}$ & $\begin{array}{l}\text { "A mãe da Kika." } \\
\text { "Está faltando os planetas." } \\
\text { "Sol girando." }\end{array}$ \\
\hline
\end{tabular}

$\mathrm{Na}$ tabela 2 observamos ainda que os alunos identificaram uma figura na qual as proporções eram incoerentes, utilizando o conceito de que existe uma distância significativa entre a Terra e o Sol e de que esse fato é importante para a ocorrência de vida no nosso planeta. Ainda nessa perspectiva, percebemos que os alunos compreenderam os movimentos de rotação e translação realizados pela Terra, a duração desses movimentos e o fato de que eles ocorrem concomitantemente. Ficou claro também que eles perceberam a existência de um eixo de rotação inclinado.

Dessa maneira, percebemos que os alunos não memorizaram os conhecimentos discutidos nas aulas, mas se apropriavam deles e conseguiram aplicá-los em outras situações, no caso o vídeo, indo ao encontro do descrito por Ausubel, citado por Moreira (1999): "a melhor maneira de evitar a 'simulação da aprendizagem significativa' é formular questões e problemas de uma maneira nova e não familiar, que requeira a máxima transformação do conhecimento adquirido.”.

$\mathrm{Na}$ segunda atividade desenvolvida nesse encontro, abordamos as diferentes construções da estrutura dos calendários solares, lunares e lunissolares, na tentativa de favorecer uma visão global sobre como as diversas culturas fazem uso das ciências naturais - da observação dos fenômenos da natureza - para medir e 
Proposta de uma sequência didática para o ensino

do tema "estações do ano" no ensino fundamental

localizar-se temporalmente. Isso é recomendado pelos PCNs, que afirmam que

Os estudantes devem ser orientados para articular informações com dados de observação direta do céu, utilizando as mesmas regularidades que nossos antepassados observaram para orientação no espaço e para medida do tempo, o que foi possível muito antes da bússola, dos relógios e do calendário atual, mas que junto a eles ainda hoje organizam a vida em sociedade em diversas culturas, o que pode ser trabalhado em conexão com o tema transversal Pluralidade Cultural (BRASIL, 2000, pág. 40).

No último encontro, os alunos entregaram os trabalhos sobre o texto "Joãozinho da Maré” solicitados no quarto encontro, após a dramatização. O principal objetivo com a realização desses trabalhos era a verificação individual do quão significativas as aulas foram para os estudantes e como estes se apropriaram dos conhecimentos construídos ao longo da sequência didática. Nesse encontro, discutimos com os alunos sobre as dúvidas apresentadas por Joãozinho no decorrer do texto e as respostas elaboradas pelos estudantes na tentativa de sanar a curiosidade de Joãozinho. Durante as discussões, os alunos fizeram várias menções ao eixo de inclinação da Terra em relação ao Sol.

A análise das redações dos alunos indicou que parte dos estudantes respondeu às dúvidas de Joãozinho com elementos contidos no próprio texto; outros se utilizaram dos conceitos desenvolvidos ao longo da sequência; e, alguns buscaram informações em outras fontes de conhecimento para explicar os questionamentos de Joãozinho.

A maioria dos estudantes (dezenove, ao todo) respondeu àss questões relacionadas com as estações do ano utilizando a inclinação do eixo de rotação da Terra como fator limitante para ocorrência desse fenômeno. Acreditamos que esse grande número de respostas foi devido à ênfase dada sobre esse assunto durante as aulas. Nas questões referentes ao horizonte leste, seis alunos responderam com elementos contidos no próprio texto, explicando que somente existe um ponto leste, mas não esclareceram a dúvida de Joãozinho de maneira adequada. Como exemplo, podemos citar um aluno que buscou uma fonte alternativa para responder a essa questão, mencionando o uso da bússola para orientação espacial. Todavia, pela resposta somos levados a crer que esse estudante se baseou em suas experiências e seus conhecimentos prévios.

Nas questões referentes ao Sol a pino, sete alunos responderam com base na definição dada pela professora do texto, a qual definia esse fenômeno, mas não esclarecia a dúvida de Joãozinho adequadamente. Sete alunos utilizaram outras fontes de informações, por exemplo, incluindo o novo conceito de que o ponto mais alto do céu é denominado de zênite, mas as resposta se aproximavam daquela dada pela professora a Joãozinho. Observamos outros exemplos de alunos que não se restringiram apenas às aulas e ao texto fornecido, sendo que a resposta de "Sol a pino" ficou bem mais completa, e, o mais importante, esses estudantes identificaram o que intrigava Joãozinho, explicando que o Sol atinge a altura máxi- 
Camila Linhares Taxini|Cintia Cristina Isicawa Puga

Caio Samuel Franciscati Silva|Rosemary Rodrigues Oliveira

ma no céu durante o verão e nas outras estações ele fica um pouco mais inclinado no horizonte.

Após a análise dessas questões somos levados a crer que a maioria dos alunos respondeu às perguntas que relacionavam as estações do ano de modo coerente porque ao longo de nossa sequência didática esse foi um conteúdo enfatizado, tanto nos textos como durante as explicações. As outras questões, referentes ao Sol a pino e ao horizonte leste, foram questões abordadas em aula de maneira superficial, e esses conceitos não estavam presentes nos textos de apoio fornecidos aos estudantes. Os alunos, ao se depararem com tais questionamentos, respondiam-nos com base no explicitado no próprio texto "Joãozinho da Maré" ou buscavam em outras fontes de informação.

Algumas redações apresentaram erros conceituais, como uma em que o aluno acreditava que nós é que estamos em movimento de translação e por isso parece que o Sol muda de lugar, o que revelou que o movimento de rotação da Terra fora confundido com o de translação.

Ao longo do desenvolvimento da sequência didática, muitos alunos revelaram confusões em relação aos termos "rotação" e "translação", evidenciando que os estudantes conhecem as definições e os desdobramentos de cada um, mas confundem os nomes. Outros estudantes (dois sujeitos) apresentavam alguns erros conceituais graves, indicando que não houve a apropriação do conceito de inclinação do eixo de rotação da Terra em relação à órbita do Sol, permanecendo o conceito anterior e mais divulgado, que relaciona as diferentes estações do ano com o maior ou menor afastamento do Sol.

\section{CONSIDERAÇÕES FINAIS}

O levantamento de literatura para este trabalho revelou que há um grande número de deficiências no ensino de Astronomia e que existem poucas pesquisas relacionadas ao assunto, sendo que a grande maioria destas detém-se no levantamento de concepções de alunos e professores. Dessa maneira, este trabalho, ao desenvolver e aplicar uma sequência de ensino sobre tal temática para crianças da educação básica, lança luzes às futuras investigações, especialmente no que se refere à construção dos saberes astronômicos em sala de aula.

Todavia, o primeiro passo para a construção significativa de intervenções pedagógicas que abordem o ensino de Astronomia é o levantamento de conhecimentos prévios dos alunos. Conhecer os saberes que os estudantes já possuem foi de extrema importância para a elaboração da sequência didática ministrada, uma vez que esse fato nos auxiliou na realização de atividades e discussões capazes de favorecer a partilha de sentidos e significados dos conteúdos para que estes se ancorassem na estrutura cognitiva dos alunos de modo a subsidiarem a construção de conhecimentos científicos aceitos socialmente, tendo como ponto de partida as concepções prévias apresentadas pelos sujeitos da pesquisa. Assim, buscamos 
oportunizar situações para que o aluno assumisse uma postura reflexiva e se tornasse sujeito do processo de ensino-aprendizagem. Nessa perspectiva, é importante destacar que o professor também assume o papel de investigador, buscando conhecer as concepções de seus alunos no início e no decorrer das diversas situações de ensino.

A utilização de diversas metodologias e modalidade didáticas mostrouse uma estratégia válida e promissora na tentativa de atender as diferenças individuais dos alunos no que se refere à maneira como eles aprendem e se apropriam dos conteúdos abordados. Aliada a essa estratégia de ensino, é importante destacar que o processo de avaliação seja coerente e condizente com os métodos e modalidades empregados. Sendo assim, o processo contínuo de avaliação adotado neste trabalho proporcionou diversas situações para que os alunos aplicassem e/ou relacionassem os conhecimentos construídos, além de possibilitar a nós, professores, diversos momentos de verificação da significância da sequência e de pontos que deveriam ser (re)ajustados e (re)vistos para se alcançar a aprendizagem significativa.

Este trabalho apresentou resultados significativos e satisfatórios para a aprendizagem de conceitos de Astronomia, em especial sobre o tema "Estações do Ano", por parte dos alunos, e consequentemente para a nossa satisfação pessoal, pois o maior contentamento de um educador é perceber que forneceu a seus educandos oportunidades para que eles se desenvolvessem intelectualmente pela aprendizagem significativa de conceitos, procedimentos ou atitudes.

\section{NOTAS}

${ }^{1}$ Mamonas Assassinas foi uma banda brasileira de rock cômico, com influências de gêneros populares tais como forró, sertanejo, além de hard rock, música portuguesa e punk rock. A referida canção, de composição de Bento e Dinho, pode ser encontrada no Cd "Mamonas Assassinas" (1995).

\section{BIBLIOGRAFIA}

ANTUNES, C. Manual de Técnicas de dinâmica de grupo de sensibilização de ludopedagogia. 23. ed. Petrópolis: Vozes, 2004. 190 p.

ARROIO, A.; DINIZ, M. L.; GIORDAN, M. A utilização do vídeo educativo como possibilidade de domínio da linguagem audiovisual pelo professor de ciências. In: ENCONTRO NACIAONAL DE PESQUISA EM EDUCAÇÃO EM CIÊNCIAS, 5, 2005, Bauru. Anais... Bauru: UNESP, 2005. p. 1-10.

BALBINOT, M. C. Uso de modelos, numa perspectiva lúdica, no ensino de Ciências. In: ENCONTRO IBERO-AMERICANO DE COLETIVOS ESCOLARES E REDES DE PROFESSORES QUE FAZEM INVESTIGAÇÃO NA SUA ESCOLA, 4, 2005, La- 
Camila Linhares Taxini|Cintia Cristina Isicawa Puga

Caio Samuel Franciscati Silva|Rosemary Rodrigues Oliveira

jeado. Anais... Lajeado: UNIVATES, 2005. p. 1-8.

BIZZO, N. Graves erros de conceito em livros didáticos de ciências. Ciência Hoje, v. 21, n.121, p.26 - 35, 1996.

BRASIL. Secretaria de Educação Média e Tecnologia. Parâmetros Curriculares Nacionais: ciências naturais. Brasília: MEC/SEMTEC, 1997.

BRASIL. Secretaria de Educação Média e Tecnologia. Parâmetros Curriculares Nacionais: ciências naturais. Brasília: MEC/SEMTEC, 2000.

CANALlE, J. B. G. Explicando astronomia básica com uma bola de isopor. Cad.Cat. Ens.Fís., v. 16, n. 3: p. 314-331, dez. 1999.

CANALLE, J. B. G.; MOURA, R. Observatórios virtuais: oficina de astronomia. Rio de Janeiro: Instituto de Física-UERJ, 1995.

CANALLE, J. B. G.; OLIVEIRA, I.A.G. Comparação entre os tamanhos dos planetas e do Sol. Cad.Cat.Ens.Fis, v.11, n.2, p.141-144, 1994.

CANALLE, J. B. G., TREVISAN, R. H. e LATTARI, C. J. B. Análise do conteúdo de astronomia dos livros de geografia de $1^{\circ}$ grau. Cad.Cat.Ens.Fís., v. 14, n.3, p.254-263, 1997. CANIATO, R. Ato de fé ou conquista do conhecimento? Um episódio na vida de Joãozinho da Maré. Boletim da Sociedade Astronômica Brasileira, v. 6, n. 2, p. 31-37, 1983.

DIAS, W. S.; PIASSI, L. P. Por que a variação da distância Terra-Sol não explica as estações do ano? Revista Brasileira de Ensino de Física, v. 29, n. 3, p. 325-329, 2007.

FONSECA, P. De onde vem: a mídia televisiva alterando o currículo escolar. 2006. 94 f. Dissertação (Mestrado em Comunicação) - Faculdade de Comunicação, Educação e Turismo, Universidade de Marília, Marília, 2006.

LANGHI, R. Um estudo exploratório para a inserção da Astronomia na formação de professores dos anos iniciais do Ensino Fundamental. 2004. 240 f. Dissertação (Mestrado em Educação para a Ciência) - Faculdade de Ciências, Universidade Estadual Paulista Júlio de Mesquita Filho, Bauru, 2004.

LEITE, C. Os professores de ciências e suas formas de pensar a astronomia. 2002. 165 p. Dissertação (Mestrado em Educação) - Instituto de Física e Faculdade de Educação, Universidade de São Paulo, São Paulo, 2002.

LEITE, C.; HOSOUME, Y. Os professores de ciências e suas formas de pensar a Astronomia. Revista Latino-Americana de Educação em Astronomia - RELEA, n. 4, p. 47-68, 2007. LIMA, E. J. M. A visão do professor de Ciências sobre as estaçoes do ano. 2006. XXX f. Dissertação (Mestrado em Ensino de Ciências e Educação Matemática) - Universidade Estadual de Londrina, Londrina,2006

MEES, A. A. Astronomia: motivação para o ensino de Física na $8^{a}$ série. 2004. 132 f. Dissertação (Mestrado Profissionalizante em Ensino de Física) - Instituto de Física, Universidade Federal do Rio Grande do Sul, Porto Alegre, 2004.

MOREIRA, M. A. Teorias de Aprendizagem. Ed. Pedagógica e Universitária, São Paulo: 1999. MOREIRA, M. A. Teorias de Aprendizagem. São Paulo: EPU, 1999. 195 p.

PERRENOUD, P. Construir as Competências desde a Escola. Tradução de Bruno Charles Magne. Porto Alegre: ArtMed, 1999. 90 p.

PUZZO, D.; TREVISAN, R. H.; LATARI, C. J. B. Astronomia: a investigação da ação 


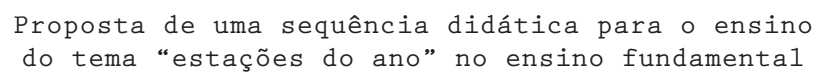

pedagógica do professor. In: ENCONTRO NACIONAL DE PESQUISA EM ENSINO DE FÍSICA 9, 2004, Jaboticatubas. Anais... Jaboticatubas: Sociedade Brasileira de Física, 2004. p. 1-13.

SÃO PAULO. Proposta Curricular do Estado de São Paulo: Ciências. São Paulo: SEE-SP, 2008. 64 p. SOBREIRA, P. H. A. Astronomia no Ensino de Geografia: análise crítica nos livros didáticos de Geografia. 2002. 276 f. Dissertação (Mestrado em Geografia Física) - Faculdade de Filosofia, Letras e Ciências Humanas, Universidade de São Paulo, São Paulo, 2002.

TIGNANELLI, H. L. Sobre o ensino da astronomia no ensino fundamental. In: WEISSMANN, H. (org.). Didática das ciências naturais: contribuições e reflexões. Porto Alegre: ArtMed, 1998. p. 57-89.

TREVISAN, R. H., LATTARI, C. J. B.; CANALLE, J. B. G., Assessoria na avaliação do conteúdo de astronomia dos livros de ciências do primeiro grau. Cad. Cat. Ens. Fís., v.14, n.1, p. 7, 1997.

Data de recebimento: $23 / 04 / 2010$

Data de aprovação: 08/10/2011

Data da versão final: 20/12/2011 